\title{
Pengaruh Pengaturan Air Fuel Ratio Terhadap Torsi dan Daya Mesin Bensin Berbahan Bakar Premium-Compressed Natural Gas
}

\author{
Oleh: \\ Bambang Junipitoyo
}

Politeknik Penerbangan Surabaya

J1. Jemur Andayani I/73 Surabaya

e-mail: ararya.pendopo@gmail.com

\begin{abstract}
ABSTRAK
Sehubungan rendahnya nilai karakteristik dan ditunjukkan pada propertisnya dari compressed natural gas (CNG) dibandingkan dengan premium, maka berdampak penurunan performa engine yang berbahan bakar asal premium.

Oleh karena itu perlu dilakukan penelitian pada engine Bensin 2 silinder $650 \mathrm{cc}$ pada variable speed 2000 - $5000 \mathrm{rpm}$ dengan interval $500 \mathrm{rpm}$, metode yang digunakan untuk mengetahui nilai settingan yang optimum adalah dengan mengatur air fuel ratio (AFR). Durasi injeksi yang digunakan pada penelitian ini sebesar $6 \mathrm{~ms}$ melalui mapping pada software AC GAS SYNCHRO 9.1.0. Sedangkan pengaturan AFR dilakukan dengan menambahkan suplai udara melalui blower dan melakukan pengukuran dengan AFR meter berdasarkan kriteria settingan durasi injeksi pada setiap putaran engine.

Hasil penelitian ini menunjukkan bahwa melalui pengaturan durasi injeksi dan nilai AFR yang tepat pada engine Bensin berbahan bakar CNG terjadi pada durasi injeksi $6.6 \mathrm{~ms}$ dengan penambahan suplai udara pada saluran intake. Hasil yang didapatkan pada pengaturan ini adalah nilai torsi, daya, secara berturut turut sebesar $41,83 \mathrm{Nm}, 16,4 \mathrm{~kW}$ atau mengalami kenaikan sebesar 1,22\%,1,12\% terhadap premium. Nilai efisiensi thermal menurun masing-masing sebesar 21,48 \%.
\end{abstract}

Kata kunci: Compressed Natural Gas, mesin bensin, daya, torsi, emisi

\section{PENDAHULUAN}

Dari tahun ke tahun jumlah kendaraan terus bertambah, sedangkan persediaan bahan bakar minyak bumi terus berkurang. Selain itu kandungan emisi gas buang (CO, $\mathrm{CO}_{2}$ dan $\mathrm{HC}$ ) yang dihasilkan oleh kendaraan yang menggunakan bahan bakar premium masih tinggi walaupun kendaraan tersebut telah menggunakan perangkat electronic control unit (ECU). Oleh karena itu studi intensif telah banyak dilakukan untuk mendapatkan bahan bakar alternatif yang sesuai untuk mesin pembakaran dalam pada kendaraan, diantaranya penelitian pada alkohol (metanol, etanol, butanol), bahan bakar gas seperti compressed natural gas (CNG), liquified petroleum gas (LPG), biogas, dan hydrogen. CNG merupakan salah satu pilihan alternatif yang sangat potensial untuk menggantikan bahan bakar cair di masa mendatang. Beberapa keuntungan dari pemanfaatan $\mathrm{CNG}$ sebagai bahan bakar alternatif pada motor bakar diantaranya, CNG merupakan bahan bakar alternatif untuk jangka panjang dan merupakan bahan bakar yang menghasilkan polutan yang rendah, menghasilkan pembakaran sempurna, selain itu harga CNG lebih murah dibandingkan bahan bakar cair. Dalam kajian eksperimen ini diharapkan agar mendapatkan nilai pengaturan durasi injeksi dan air fuel ratio yang maksimal serta nilai unjuk kerja yang dinyatakan dalam: torsi, daya, effisiensi thermal, effisiensi volumetric, sfc, bmep dan emisi gas buang antara motor bensin standar dan pemakaian bahan bakar CNG. Hasil penelitian ini tentunya akan menjadi rekomendasi bagi pengguna bahan bakar CNG untuk 
meminimalisir kekurangan-kekurangan yang ada dalam penggunaan bahan bakar tersebut.

\section{METODE}

Penelitian ini dilakukan dengan menggunakan metode eksperimental. Pengujian dilakukan pada engine Bensin 4 langkah dengan kapasitas engine $650 \mathrm{cc}$ single fuel gasoline engine yang dimodifikasi menjadi bi-fuel engine, yaitu dengan menggunakan bahan bakar gasoline dan compressed natural gas (CNG). Untuk mendapatkan kinerja engine yang baik, khususnya daya, dilakukan pengaturan durasi injeksi (injection time) dan air fuel ratio dengan diuji menggunakan waterbrake chasis dynamometer dan AFR meter. Untuk mengetahui kadar emisi gas buang dilakukan pengukuran dengan menggunakan gas analyzer. Proses modifikasi mesin dan seluruh rangkaian pengujian dilakukan di Laboratorium Motor Bakar. Hasil yang diharapkan dari penelitian untuk mendapatkan nilai pengaturan durasi injeksi dan air fuel ratio yang maksimal serta nilai unjuk kerja yang dinyatakan dalam: daya, torsi, bmep, efisiensi termal, efisiensi volumetris dan emisi gas buang ( $\mathrm{CO}$ dan $\mathrm{HC}$ ). Penelitian ini dibagi menjadi dua kelompok yaitu:

* Pengujian single fuel engine dengan menggunakan bahan bakar premium.

* Pengujian bi-fuel engine menggunakan bahan bakar compressed natural gas (CNG) dan menggunakan variasi durasi injeksi dan penggaturan air fuel ratio.

Adapun layout engine test sebagai berikut:

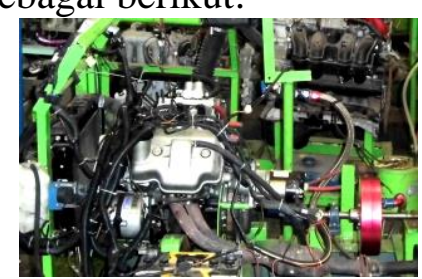

Gambar 1. Layout Penelitian

Selain engine test di atas adapun layout untuk melakukan switching dari engine berbahan bakar premium ke bahan bakar CNG (bi-fuel) seperti berikut:

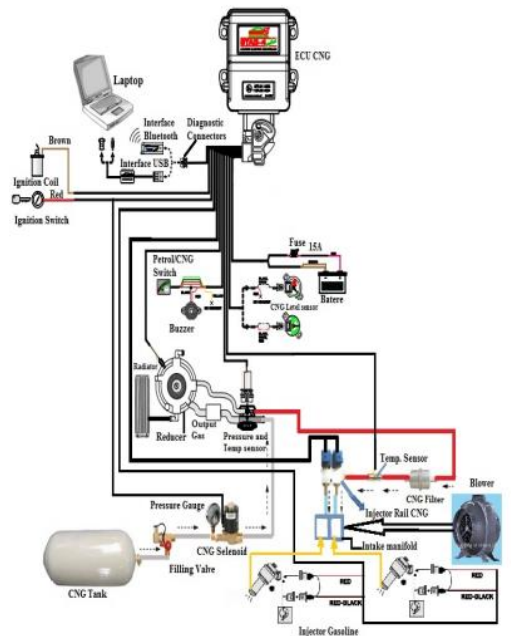

Gambar 2. Skema converter kit pada bahan bakar tipe bi-fuel. 
Dalam melakukan pengujian eksperimen maka dimulai dengan melakukan urutan sebagai berikut:

1) pengujian engine dengan menggunakan bahan bakar premium tanpa dilakukan modifikasi.

2) pengujian engine dengan menggunakan bahan bakar CNG tanpa dilakukan modifikasi.

\section{HASIL DAN PEMBAHASAN}

Setelah mengadakan penelitian, maka data yang diperoleh perlu dideskripsikan terlebih dahulu kemudian dianalisis hasilnya dan digrafikkan, tujannya adalah untuk menjelaskan data yang diperoleh agar tidak terjadi perbedaaan dalam mempersepsikan data. Berikut analisa data pada pengujian eksperimen ini adalah sebagimana berikut:

1) Analisa Torsi Engine Tiap Mapping Injection Time.

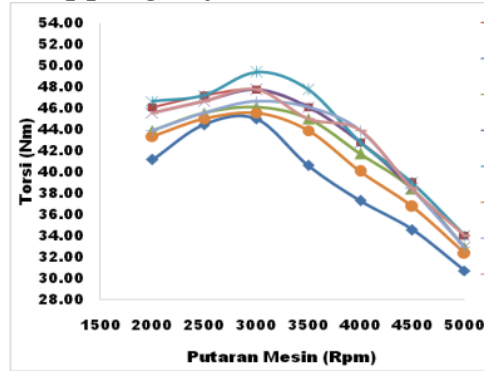

Gambar 3. Grafik Torsi terhadap Putaran Mesin

Analisa data pada saat engine menggunakan bahan bakar CNG dengan settingan injection time $6.6 \mathrm{~ms}$ ketika engine menggunakan blower dan tidak menggunakan blower pada saluran intake manifold. Saat dilakukan settingan injection time sebesar $6.6 \mathrm{~ms}$ terjadi penurunan nilai torsi rata-rata pada semua putaran engine (2000-5000 rpm), masing-masing sebesar 3,08\% saat menggunakan blower dibandingkan saat engine menggunakan bahan bakar premium, akan tetapi jika nilai settingan injection time $6.6 \mathrm{~ms}$ tersebut dibandingkan dengan saat engine menggunakan bahan bakar CNG dengan setingan ECU standar hasil kalibrasi, maka terjadi kenaikan nilai torsi rata-rata pada putaran engine (2000-5000 rpm), yaitu sebesar 7,28\% saat menggunakan blower.

\section{2) Analisa Daya Engine Tiap Mapping Injection Time}

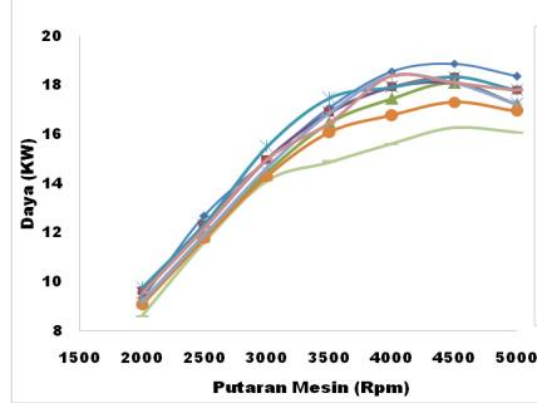

Gambar 4. Grafik Daya terhadap Putaran Mesin

Berdasarkan grafik di atas, pada pemakaian bahan bakar CNG injection time (ms) disetting dengan ukuran 6.6ms dari injection time (ms) standar ECU saat kalibrasi, baik saat yang menggunakan blower maupun yang tidak menggunakan blower pada intake manifold. Saat dilakukan settingan injection time sebesar $6.6 \mathrm{~ms}$ terjadi penurunan nilai daya rata-rata pada semua putaran engine (2000-5000 rpm), masing-masing sebesar $2,87 \%$ saat menggunakan blower dibandingkan saat engine menggunakan bahan bakar 
premium, akan tetapi jika nilai settingan injection time $6.6 \mathrm{~ms}$ tersebut dibandingkan dengan saat engine menggunakan bahan bakar CNG dan terdapat penambahan nilai daya pada putaran engine (2000-5000 rpm), yaitu sebesar 7,87\% saat menggunakan blower.

\section{KESIMPULAN}

Berdasarkan hasil analisis data dan pembahasan, dapat disimpulkan bahwa:

1. Dapat dilakukan rancangan mekanisme pemasukan CNG ke dalam sistem bahan bakar bi-fuel pada mesin Bensin dengan baik.

\section{DAFTAR PUSTAKA}

Jahirul. M.I, Masjuki, H.H., Saidur, R., Jayed, M.H., dan Wazed, M.A., (2010). "Comparative engine performance and emission analysis of CNG and gasoline in a retrofitted car engine". Applied Thermal Engineering. (2010) hal 22192226.

Kalam, M.A., Masjuki H. H., (2011), “An experimental investigation of high performance natural gas engine with direct injection", Kuala Lumpur, Malaysia: Department of Mechanical Engineering, University of Malaysia.

Pulkrabek, Willard W (1997), Internal Combustion Engine, Prentice Hall, New Jersey. Sera, A.M., Bakar, A.R. dan Leong, K.S. "Effect of fuel density on the performance of a CNG fuelled engine" Fakulti Kejuruteraan Mekanikal Universiti Teknologi Malaysia, 81310 UTM Skudai Johor Darul Ta'zim Malaysia.

Yousufuddin, S., Venkateswarlu, K. dan Khan, Naseeb. (2012), "Effect of Equvalence Ratio on The Performance of An Engine Running at Various Speed Fuelled With Gasoline and Natural Gas", International Journal of Advanced Science and Technology, Vol.43. 